\title{
Bioinformatics-Based Prediction of FUT8 as a Therapeutic Target in Estrogen Receptor-Positive Breast Cancer
}

\author{
Fateme Shaabanpour Aghamaleki ${ }^{1}$, Shirin Farivar ${ }^{1, *}$ \\ ${ }^{1}$ Department of Cellullar-Molecular Biology, Faculty of biological Sciences and \\ technologies, Shahid Beheshti University G.C., Tehran, Iran
}

*Corresponding author: Shirin Farivar,Department of Cellullar-Molecular Biology, Faculty of biological Sciences and technologies, Shahid Beheshti University G.C., Tehran, Iran. Tel: +982129902720; Fax: +982122431664;

E-mail: s_farivar@sbu.ac.ir

DOI: $10.30699 /$ acadpub.mci.3.1.25

Submitted: 20 October 2018

Revised: 4 November 2018

Accepted: 28 November 2018

e-Published: 1 January 2019

\section{Keywords:}

Fucosyltransferases

Breast Neoplasms

Microarray Analysis

Signal Transduction

\begin{abstract}
Introduction: Estrogen receptor-positive (ER-positive) breast cancer is a subgroup of breast tumors that is more likely to respond to hormone therapy. ER-positive and ERnegative breast cancers tend to show different patterns of metastasis because of different signaling cascade and genes that are activated by estrogen response. Genetic factors can contribute to high rates of metastasis in ER-positive breast cancer. Fucosyltransferase 8 (FUT8) is a member of fucosyltransferases family and plays an important role in $\alpha-1,6$ linkage to the first GlcNAc residue of N-glycans chain. In this study, for the first time, we predicted FUT8 by bioinformatics tools as a novel therapeutic target for ER-positive breast cancer.
\end{abstract}

Methods: Microarray gene expression data of 9 patients with ER+ve and 10 individuals with ER-ve breast cancer was extracted from Geodatasets. Gene expression of two ER+ and ER-patients was compared with logfc and then sorted by their p-values. Moreover, the most related pathway, protein interaction, and function of this gene were identified with GeneCard and DAVID databases.

Results: FUT8 was highly expressed in patients with ER+ve breast cancer that may be associated with the metastasis. FUT8 encodes an enzyme that belongs to fucosyltransferases family. The expression of this gene may contribute to the malignancy features of cancer cells and their invasive and metastatic capabilities.

Conclusions: Having in mind FUT8 hyperexpression, its function in malignancy, and its pathways, it can be concluded that FUT8 can be used as a therapeutic target in ER+ve breast cancer.

(C) 2019. Multidisciplinary Cancer Investigation

\section{INTRODUCTION}

Breast cancer is one of the most prevalent malignancies in women with 4 major types according to the presence of sex hormone receptors on the cancer cell. Endocrine receptor-positive (estrogen or progesterone receptors), HER2-positive, triple positive (these tumors are positive for estrogen receptors, progesterone receptors, and HER2), and triple negative (these tumors are not positive for estrogen receptors, progesterone receptors, and HER2) tumors are the main categories of breast cancer [1-3]. About $80 \%$ of all breast cancers are estrogen receptor-positive (ER-positive) that may 
influence the growth of cancer cells in response to the estrogen [4-6]. About $65 \%$ of breast tumors are progesterone receptor-positive (PR-positive) which grow in response to another sex hormone called progesterone [7-9]. These hormones especially estrogen, play an important role in cell cycle and tumor progression $[4,10,11]$. Estrogens are considered to play a major role in promoting the proliferation of normal and neoplastic breast epithelial cells. Three major mechanisms are suggested to be involved in estrogen carcinogenic effects: 1. Stimulation of cellular proliferation through estrogens receptor-mediated hormonal activity. Actually, when hormones bind to the cell surface receptors, hormone-responsive genes and signaling cascades including MAPK signaling and PI3K signaling pathways, are turned on for DNA synthesis and cell proliferation. 2. Increasing mutation level through a cytochrome P450-mediated metabolic activation. Cytochrome P-450 catalyzes the oxidative metabolism of estrogen and estradiol to a 2-hydroxycatechol estrogen that can induce genetic mutations. 3. Induction of aneuploidy including loss of 9p11-13 and 4p15.3-16 deletion that have been introduced to be tumorigenic in several studies [12-14]. In addition, genetic factors play an important role in breast cancer initiation and progression. Among genetics element, somatic mutations happen more frequently in breast cells [15] However, some patients show a germline mutation in BRCA1 and BRCA2 genes. These genes are used in many prediction tests for breast cancer in patients with a familial background [16-18]. Some of the important genes are expressed only after activating the estrogen receptor and affect both normal and cancer cells. Therefore, identification of molecular keys in breast cancer can result in better decision making about breast cancer treatment. In this article, Microarray gene expression data of breast cancer patients were studied from Geodatabase to identify critical and different genes between ER-positive and ER-negative breast cancer.

\section{METHODS}

\section{Gene Profile Extraction}

Microarray gene expression data of 9 cases with $\mathrm{ER}+\mathrm{ve}$ and 10 patients with ER-ve breast cancer (GSE32394) were extracted from NCBI Geodatasets [19]. This profile included samples of ER+ve and
ER-ve patients that were submitted in September 2011 and updated in April 2017.

\section{Gene Expression Profile Analysis}

This profile was analyzed; using limma package in $\mathrm{R}$ program. Limma is an $\mathrm{R} /$ Bioconductor package and a powerful differential expression analyzing tool for RNA-sequencing and microarray studies [20, 21]. Generated unnormalized data were normalized by robust multiarray averaging (RMA) method. To determine data value and their normalization, the distribution of the samples was performed. In this step, genes were compared based on their log fold change (logfc) and their level of expression between ER+ve and ER-ve breast cancer patients. They were then sorted into hyperexpressed genes in ER+ve patients and hypoexressed genes in ERve breast cancer individuals according to their $\mathrm{p}$-value and vice versa to determine specific gene in ER+ve breast cancer. Moreover, the expression level of a gene of interest was determined among all 19 samples through the profile graph in NCBI Geodatasets. Finally, a gene that was hyperexpressed and had the lowest p-value in ER+ve breast cancer patients was chosen for further analysis. The most related pathway (Gene Ontology) and function of the gene of interest were identified by the GeneCard and DAVID databases for understanding its effect in the pathogenesis of ER+ breast tumor.

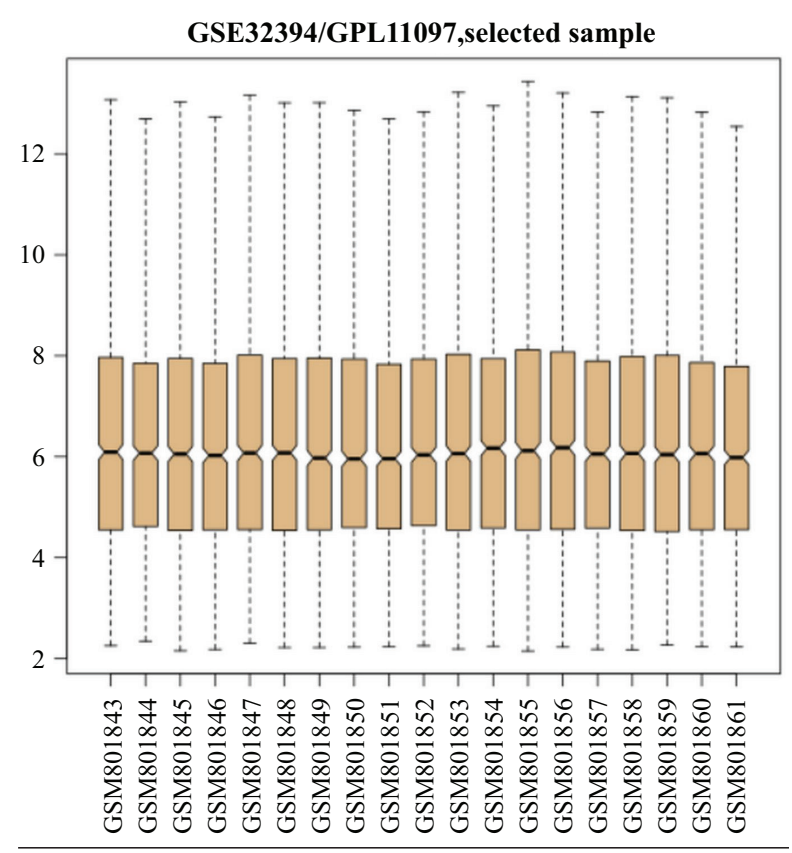

Figure 1: Distribution of Data Value: Distribution Can Be Viewed by Box Plot to Indicate Data Value and Normalization 
GSE32394/NM_178155.1_psr1_a_at/FUT8

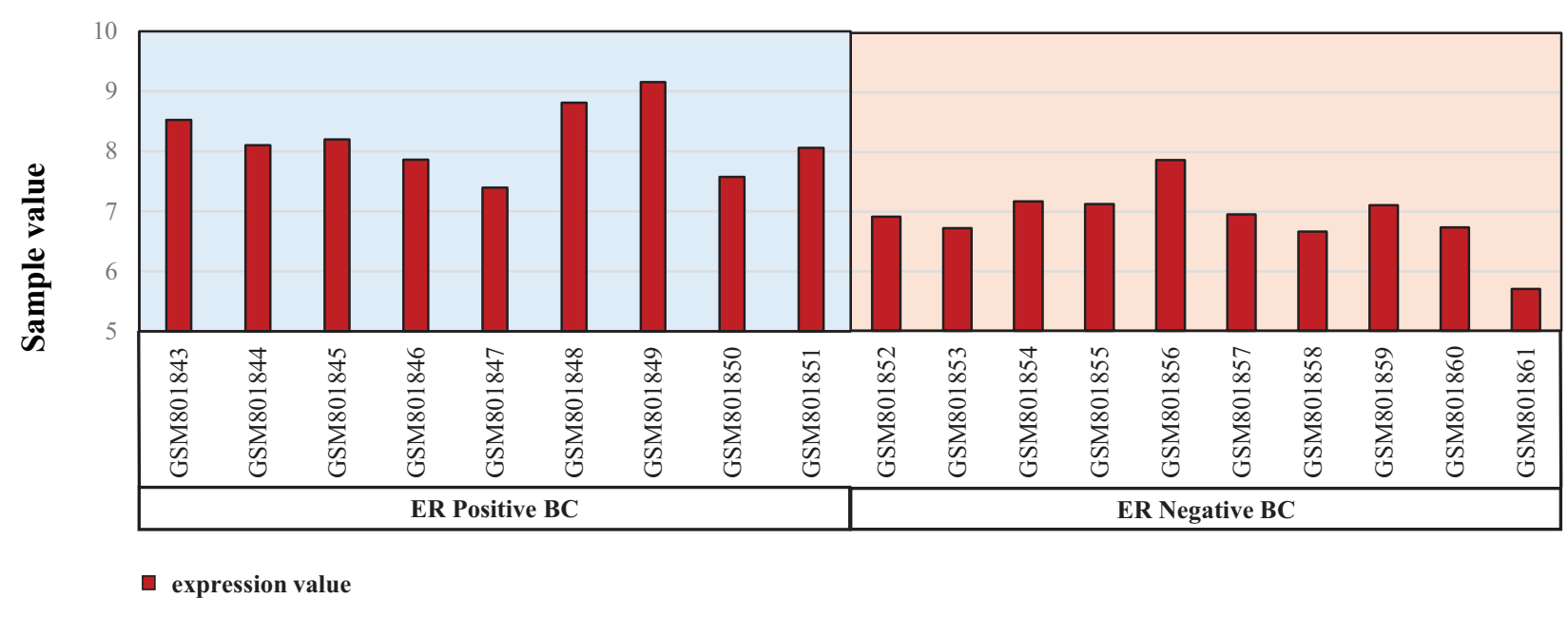

Figure 2: Different Expression Level of FUT8 Was Observed Among ER+ and ER-ve Breast Cancer (GSM Indicates Samples).

\section{GSE32394/GPL11097/NM 178155.1_psr1_a at}

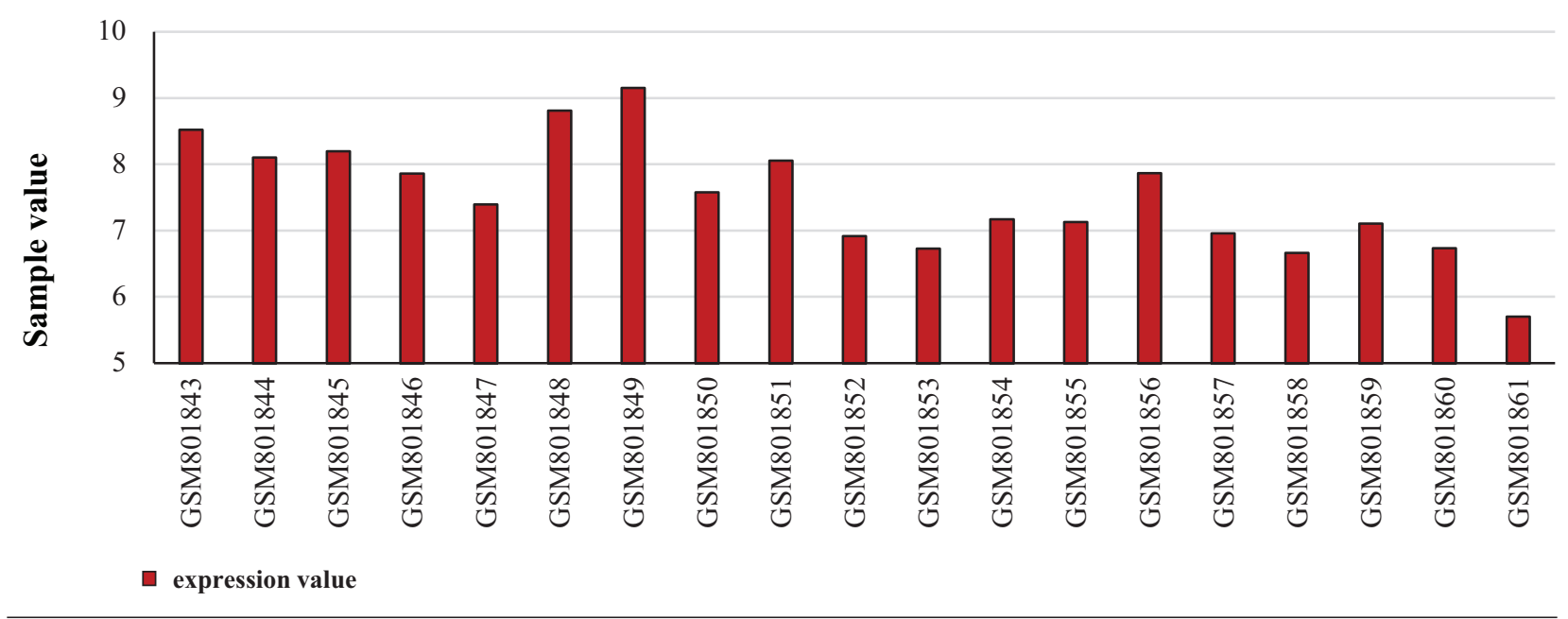

Figure 3: FUT8 Expression Among All Samples

The interaction of the protein product of this gene with other proteins was also identified to confirm its activity through STRING databases.

\section{RESULTS}

According to the analysis of distributed data value and its box plot, it was concluded that it can be a valuable microarray data for gene expression analysis (Figure 1). FUT8 was hyperexpressed with $2.2064 \operatorname{logfc}$ in ER+ve breast cancer patients compared to ER-ve breast cancer patients through gene expression profile analysis (Figure 2). This gene is located on 14q23.3 and encodes a protein with 575 aa and has SH3_9 SH3_1 SKI NodZ motifs.
FUT8 expression was identified among 19 samples to recognize its overexpression in all samples (Figure 3). According to this figure, it's determined that FUT8 was hyperexpressed in nearly all of the samples.

Important pathways of FUT8 included N-glycan synthesis pathway, biosynthesis of keratan sulfate, and transcriptional misregulation based on GeneCard and DAVID databases (Figure 4). N-glycan synthesis pathway plays an important role in cancer invasion and metastasis. N-glycan, which is synthesized by FUT8, exhibits in a number of glycoproteins such as EGFR, IGFR, and FGFR. Recently, N-glycan synthesis pathway and biosynthesis of keratan sulfate are considered as therapeutic targets for cancer. 
A

GLYCOSAMINOGLYCAN BIOSYNTHESIS -KERATAN SULFATE

N-Glycan biosynthesis

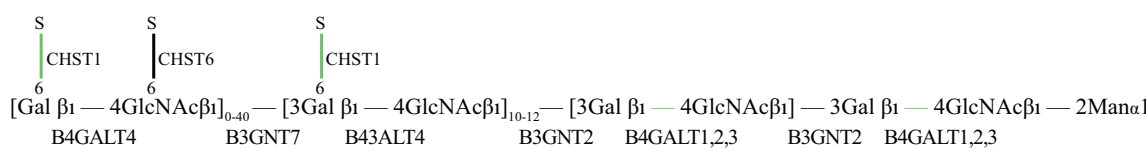

${ }_{3}^{6} \mathrm{Man} \beta 1-4 \mathrm{GlsNAc} \beta 1-4 \mathrm{GlcNAc}-\mathrm{Asn}_{{ }_{6}}$ FUT8

NeuNAca2-3Gal $\beta 1-4 \mathrm{GlcNAc} \beta 1-2 \mathrm{Man} \alpha 1$

ST3GAL3 B4GALT1,2,3

Keratan sulfate I (KSI)

B

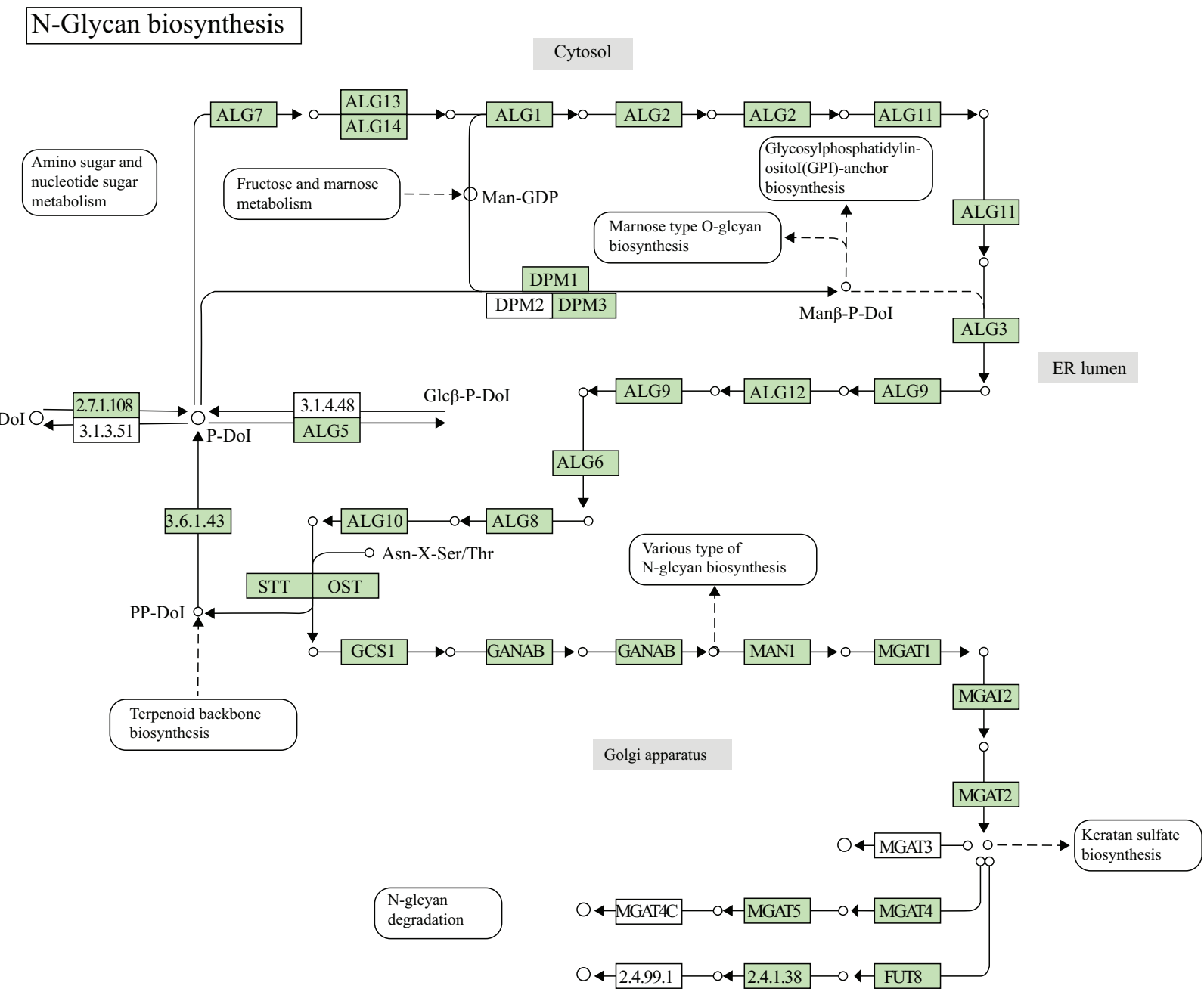

Figure 4: A) Keratan Sulfate Biosynthesis; B) N-Glycan Biosynthesis Pathway

FUT8 protein product interaction with apoptotic chromatin condensation inducer 1 (ACIN1) and DEAH-box helicase 15 (DHX15) indicates its role in tumorigenesis, according to STRING database (Figure 5). A nuclear protein is encoded by ACIN1 that induces apoptotic chromatin condensation 
after being activated by caspase-3, without induction of DNA fragmentation [22]. Having in mind this pathway, ACIN1 plays a crucial role in breast neoplasms [23]. DHX15 is involved in premRNA processing and helicase activity and has a critical function in breast carcinoma, glioma, and prostate cancer $[24,25]$. According to this protein interaction, it can be expected that FUT8 upregulation may play a critical role in $\mathrm{ER}+\mathrm{ve}$ breast cancer.

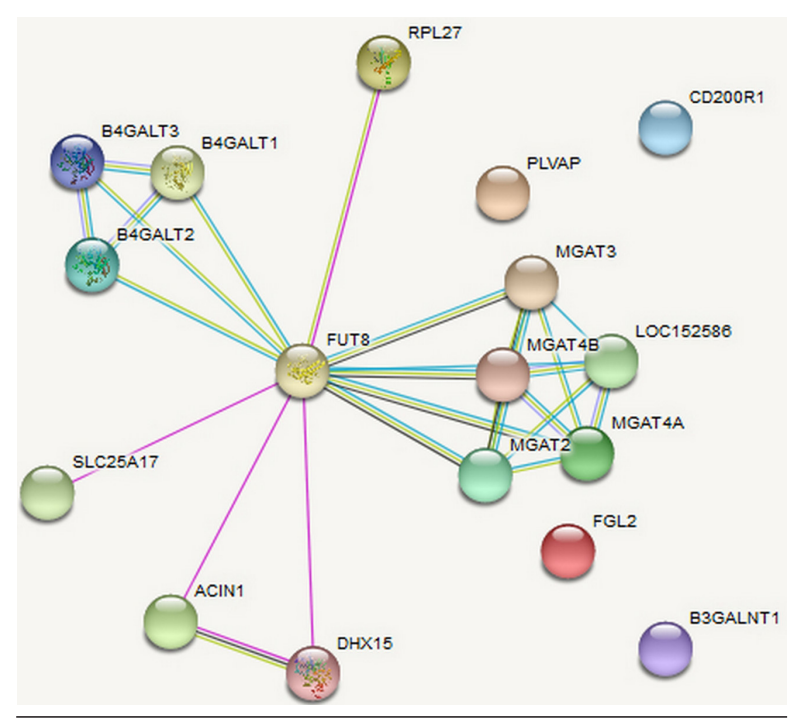

Figure 5: Experimentally Approved FUT8 Interaction With Other Protein Such As ACIN1 and DHX15

\section{DISCUSSION}

Breast cancer is one of the most prevalent types of cancer in women involving patients aged 40-50 years old [26]. So far, about 13 FUTs have been recognized, while only FUT8 is involved in core fucosylation (adding fucose in $\alpha-1,6$-linkage to the innermost $\mathrm{N}$-acetyl glucosamine of $\mathrm{N}$-glycans). The regulatory function of adhesion molecules and growth factor receptors, such as $\alpha 3 \beta 1$ integrin, epidermal growth factor receptor, and hepatocyte growth factor receptor is core fucosylation of glycoproteins has important. Fucosyltransferase 8 (FUT8) belongs to fucosyltransferases family $[27,28]$. Transfer of fucose from GDP-fucose to N-linked type complex glycopeptides on the cell surface is catalyzed by the product of this gene. FUT8 is one of the most important genes; playing a key role in malignancy and metastasis since fucosylation is essential for EGF receptor-mediated biological functions. Furthermore, fucosylation of glycoproteins regulates several biological functions of adhesion molecules and growth factor receptors. FUT8 is upregulated in several types of cancers including, nonsmall cell lung cancer, hepatocarcinoma, ovarian cancer, lung cancer, colorectal cancer, melanoma and skin cancer $[29,30]$. This is the first bioinformatics study that evaluates the FUT8 gene expression in ER+ve breast cancer; suggesting that the FUT8 gene expression is related to the incidence of ER+ve breast tumors. A significantly increased expression of FUT8 was observed in ER+ve breast cancer. These findings suggest that upregulated expression of FUT8 in ER+ breast tumors may mimic phenotypic characteristics of malignant tumor cells against estrogen that may be correlated to the high rate of metastasis in ER+ve breast cancer. Moreover, we found that the addition of N-glycan fucosylation to EGFR can occur by FUT8 according to the FUT8 role in N-glycan synthesis. Several studies have shown that increased fucosylation of EGFR, promoted a significant EGFmediated cellular growth and proliferation in cancers such as melanoma, colorectal, and prostate cancer; highlighting FUT8 role in ER+ve breast cancer [28, $31,32]$. Generally, glycosylation of cell surface receptors including EGFR is important in cancer biology processes such as cellular proliferation and metastasis. Therefore, aberrant expression of FUT8 in these types of tumors would change the level of fucose in EGFR which can lead to high cell proliferation and metastasis in ER+ve breast cancer cell. In addition, having in mind the FUT8 interaction with ACIN1 and DHX15 with major effect on breast cancer, it is expected that FUT8 can have an effect on breast cancer as well [33]. These findings showed the critical role of FUT8 in ER+ breast cancer. However, experimental studies are required to approve the role of FUT8 in ER+ve breast cancer.

To the best of our knowledge, this was the first study that described FUT8 gene expression in ER+ breast cancer for the first time. Our results demonstrated that increased expression of FUT8 in ER+ breast cancer may be important in the acquisition of an aggressive phenotype and tumor metastasis that is more typically found in ER+ breast cancer rather than ER- breast cancer. In addition, our study introduced FUT8 expression as a therapeutic modality for target therapies including, CRISPR/Cas9 technique, genetic engineering, and gene therapy.

\section{ACKNOWLEDGMENTS}

Not applicable. 


\section{CONFLICT OF INTEREST}

The authors declared no conflict of interest.

\section{ETHICS APPROVAL}

This study is a bioinformatic study and is approved by SBU university.

\section{REFERENCES}

1. Parks RM, Derks MGM, Bastiaannet E, Cheung KL. Breast Cancer Epidemiology. In: Wyld L, Markopoulos C, Leidenius M, Senkus-Konefka E, editors. Breast Cancer Management for Surgeons. 1 ed: Springer International Publishing; 2018. p. 19-29.

2. Tao Z, Shi A, Lu C, Song T, Zhang Z, Zhao J. Breast cancer: epidemiology and etiology. Cell Biochem Biophys. 2015;72(2):333-8. DOI: 10.1007/s12013-014-0459-6 PMID: 25543329

3. Lehmann BD, Bauer JA, Chen X, Sanders ME, Chakravarthy AB, Shyr Y, et al. Identification of human triple-negative breast cancer subtypes and preclinical models for selection of targeted therapies. J Clin Invest. 2011;121(7):2750-67. DOI: $10.1172 /$ JCI45014 PMID: 21633166

4. Shou J, Massarweh S, Osborne CK, Wakeling AE, Ali $\mathrm{S}$, Weiss $\mathrm{H}$, et al. Mechanisms of tamoxifen resistance: increased estrogen receptor-HER $2 /$ neu cross-talk in ER/HER2-positive breast cancer. J Natl Cancer Inst. 2004;96(12):926-35. PMID: 15199112

5. Pietras RJ, Arboleda J, Reese DM, Wongvipat N, Pegram MD, Ramos L, et al. HER-2 tyrosine kinase pathway targets estrogen receptor and promotes hormone-independent growth in human breast cancer cells. Oncogene. 1995;10(12):2435-46. PMID: 7784095

6. McGuire WL. Estrogen receptors in human breast cancer. J Clin Invest. 1973;52(1):73. DOI: 10.1172/JCI107175 PMID: 4345203

7. Anderson WF, Chatterjee N, Ershler WB, Brawley OW. Estrogen receptor breast cancer phenotypes in the Surveillance, Epidemiology, and End Results database. Breast Cancer Res Treat. 2002;76(1):27-36. PMID: 12408373

8. Boyle P. Triple-negative breast cancer: epidemiological considerations and recommendations. Ann Oncol. 2012;23(suppl_6):vi7-vi12. DOI: 10.1093/annonc/mds187 PMID: 23012306

9. Bauer KR, Brown M, Cress RD, Parise CA, Caggiano V. Descriptive analysis of estrogen receptor (ER)-negative, progesterone receptor (PR)-negative, and HER2-negative invasive breast cancer, the so-called triple-negative phenotype. Cancer. 2007;109(9):1721-8. DOI: 10.1002/ cncr.22618 PMID: 17387718

10. Biswas DK, Cruz AP, Gansberger E, Pardee AB. Epidermal growth factor-induced nuclear factor $\kappa \mathrm{B}$ activation: a major pathway of cell-cycle progression in estrogen-receptor negative breast cancer cells. Proc Natl Acad Sci USA. 2000;97(15):8542-7. DOI: 10.1073/pnas.97.15.8542 PMID: 10900013

11. Finn RS, Dering J, Conklin D, Kalous O, Cohen DJ, De- sai AJ, et al. PD 0332991, a selective cyclin D kinase 4/6 inhibitor, preferentially inhibits proliferation of luminal estrogen receptor-positive human breast cancer cell lines in vitro. Breast Cancer Res. 2009;11(5):R77. DOI: 10.1186/ bcr2419 PMID: 19874578

12. Russo J, Russo IH. The role of estrogen in the initiation of breast cancer. J Steroid Biochem Mol Biol. 2006;102(15):89-96. DOI: 10.1016/j.jsbmb.2006.09.004 PMID: 17113977

13. Miller K. Estrogen and DNA damage: the silent source of breast cancer? J Natl Cancer Inst. 2003;95(2):100-2. PMID: 12529340

14. Hertz R. The estrogen-cancer hypothesis. Cancer. 1976;38(1 SUPPL):534-40. $\quad$ PMID: 1277106

15. Olopade OI, Fackenthal JD. Breast cancer genetics. Hematology/Oncology Clinics. 2000;14(3):705-25.

16. Nathanson KN, Wooster R, Weber BL. Breast cancer genetics: what we know and what we need. Nat Med. 2001;7(5):552-6. DOI: 10.1038/87876 PMID: 11329055

17. McPherson K, Steel C, Dixon J. ABC of breast diseases: breast cancer-epidemiology, risk factors, and genetics. BMJ. 2000;321(7261):624. DOI: 10.1136/ bmj.321.7261.624 PMID: 10977847

18. Rahman N, Seal S, Thompson D, Kelly P, Renwick A, Elliott A, et al. PALB2, which encodes a BRCA2-interacting protein, is a breast cancer susceptibility gene. Nat Genet. 2007;39(2):165-7. DOI: 10.1038/ng1959 PMID: 17200668

19. Julien S, Ivetic A, Grigoriadis A, QiZe D, Burford B, Sproviero D, et al. Selectin ligand sialyl-Lewis $\mathrm{x}$ antigen drives metastasis of hormone-dependent breast cancers. Cancer Res. 2011;71(24):7683-93. DOI: 10.1158/00085472.CAN-11-1139 PMID: 22025563

20. Ritchie ME, Phipson B, Wu D, Hu Y, Law CW, Shi W, et al. limma powers differential expression analyses for RNA-sequencing and microarray studies. Nucleic Acids Res. 2015;43(7):e47-e. DOI: 10.1093/nar/gkv007 PMID: 25605792

21. Smyth GK. Limma: linear models for microarray data. In: Gentleman R, Carey V, Dudoit S, Irizarry R, Huber W, editors. Bioinformatics and computational biology solutions using $\mathrm{R}$ and Bioconductor. New York: Springer; 2005. p. 397-420.

22. Sahara S, Aoto M, Eguchi Y, Imamoto N, Yoneda Y, Tsujimoto Y. Acinus is a caspase-3-activated protein required for apoptotic chromatin condensation. Nature. 1999;401(6749):168-73. DOI: 10.1038/43678 PMID: $\underline{10490026}$

23. Kibriya MG, Jasmine F, Roy S, Paul-Brutus RM, Argos M, Ahsan H. Analyses and interpretation of whole-genome gene expression from formalin-fixed paraffin-embedded tissue: an illustration with breast cancer tissues. BMC Genomics. 2010;11(1):622. DOI: 10.1186/1471-2164-11-622 PMID: 21059268

24. Stan R-V, Arden KC, Palade GE. cDNA and protein sequence, genomic organization, and analysis of cis regulatory elements of mouse and human PLVAP genes. Genomics. 2001;72(3):304-13. DOI: 10.1006/geno.2000.6489 PMID: $\underline{11401446}$

25. Xu L, Tan AC, Winslow RL, Geman D. Merging microar- 
ray data from separate breast cancer studies provides a robust prognostic test. BMC Bioinformatics. 2008;9(1):125. DOI: 10.1186/1471-2105-9-125 PMID: 18304324

26. Youlden DR, Cramb SM, Dunn NA, Muller JM, Pyke CM, Baade PD. The descriptive epidemiology of female breast cancer: an international comparison of screening, incidence, survival and mortality. Cancer Epidemiol. 2012;36(3):23748. DOI: 10.1016/j.canep.2012.02.007 PMID: 22459198

27. Yamaguchi Y, Fujii J, Inoue S, Uozumi N, Yanagidani S, Ikeda Y, et al. Mapping of the alpha-1,6-fucosyltransferase gene, FUT8, to human chromosome 14q24.3. Cytogenet Cell Genet. 1999;84(1-2):58-60. DOI: 10.1159/000015215 PMID: 10343104

28. Wang X, Gu J, Ihara H, Miyoshi E, Honke K, Taniguchi N. Core fucosylation regulates epidermal growth factor receptor-mediated intracellular signaling. J Biol Chem. 2006;281(5):2572-7. DOI: 10.1074/jbc.M510893200 PMID: 16316986

29. Miyoshi E, Moriwaki K, Nakagawa T. Biological function of fucosylation in cancer biology. $\mathrm{J}$ Biochem. 2008;143(6):725-9. DOI: 10.1093/jb/mvn011 PMID:

\section{$\underline{18218651}$}

30. Chen C-Y, Jan Y-H, Juan Y-H, Yang C-J, Huang M-S, Yu C-J, et al. Fucosyltransferase 8 as a functional regulator of nonsmall cell lung cancer. Proc Natl Acad Sci USA. 2013;110(2):630-5. DOI: 10.1073/pnas.1220425110 PMID: 23267084

31. Liu Y-C, Yen H-Y, Chen C-Y, Chen C-H, Cheng P-F, Juan Y-H, et al. Sialylation and fucosylation of epidermal growth factor receptor suppress its dimerization and activation in lung cancer cells. Proc Natl Acad Sci USA. 2011;108(28):11332-7. DOI: 10.1073/pnas.1107385108 PMID: 21709263

32. Matsumoto K, Yokote H, Arao T, Maegawa M, Tanaka K, Fujita Y, et al. N-Glycan fucosylation of epidermal growth factor receptor modulates receptor activity and sensitivity to epidermal growth factor receptor tyrosine kinase inhibitor. Cancer Sci. 2008;99(8):1611-7. DOI: 10.1111/j.13497006.2008.00847.x PMID: 18754874

33. Weinhausel A, Gyurjan I, inventors; Google Patents, assignee. Breast cancer diagnostic method and means. 2016. 